\title{
TOWARDS AN AUTONOMOUS MANAGEMENT MAINTENANCE MODEL APPLIED TO A HERITAGE BUILDING: THE CASE OF HERNANDO COLÓN COLLEGE, UNIVERSIDAD DE SEVILLA, SPAIN
}

\author{
MIGUEL LEÓN-MUÑOZ, DAVID BIENVENIDO-HUERTAS \& CARLOS RUBIO-BELLIDO \\ Department of Building Construction II, Universidad de Sevilla, Spain
}

\begin{abstract}
Maintenance in buildings is crucial to assure a proper use during their lifespan. However, both unqualified managers and a lack of commitment to develop a maintenance management plan is a challenge to establish Total Productive Maintenance (TPM) and European Foundation for Quality Management (EFQM) models. Moreover, if a building comprises heritage special requirements, specific actions must be considered. In this context, this research proposes a maintenance methodology by unqualified managers to facilitate decision-making for qualified agents. For this purpose, process management provides the bases for an autonomous management maintenance model characterisation and its application to historic buildings. Hernando Colón College (CMHC by its abbreviation in Spanish) of the University of Seville is a superb example of a heritage building with maintenance data and track record in process management approach, which supposes a starting point to apply the proposed methodology. The model has been implemented in the CMHC since 2015. The results showed that the maintenance optimisation reduced the number of corrective maintenance actions by $13 \%$ in comparison with the preventive actions. The results also indicated that the total maintenance actions were reduced by $37 \%$. This study demonstrates, by collecting data based on quantitative measures, that it is possible to apply an autonomous maintenance management model in a historic building in use.

Keywords: building maintenance, management, TPM, human factor, lifespan.
\end{abstract}

\section{INTRODUCTION}

Building elements are degenerated during buildings' lifespan because of the pass of time, external agents, sporadic accidents, and buildings' use, so they should be appropriately repaired. This degradation, generally of lesser importance, does not impede the correct operation of the element, so users are not aware of the degradation from the first moment. Occasionally, this fact results in more serious damages, even irreversible, thus taking more expensive actions. However, this cost increase could be avoided by previously detecting it and taking the appropriate measures. Equally, owners consider some of these damages as inevitable, just repairing the elements that affect building's habitability.

It is therefore essential to take a set of actions that always ensure the good operation, predicting the possible risks that could affect building's security and protecting environment from possible aggressions. Building maintenance management has not been deeply studied as it is thought that, after buildings are constructed, their durability is guaranteed forever.

In Spain the law [1] forces buildings' owners and users to correct and to maintain buildings appropriately; however, there is no legislation that regulates and indicates the professional who should manage this aspect or the requirements that should be fulfilled.

From the industrial point of view it is said that "business suffers because maintenance is not enough considered" [2], so from the building point of view it could be said that "the lifespan of our buildings is reduced because their maintenance is not enough considered". 
If the maintenance of our in-use buildings with certain heritage value is managed, time of lifespan is gained and, to a lesser extent, the capacity, the use and the improvement of rooms and installations are increased, thus guaranteeing a comfortable environment, and facilitating safer spaces.

The aim is not just the cost reduction by adjusting the maintenance effectiveness, but achieving a total productive maintenance (TPM), which is already implemented in the industrial sector by easily making all managers, owners, and users party to heritage buildings. All this is based on management strategies and processes to be studied in relation to the various uses, future strategies, and construction possibilities.

This research work presents an intuitive tool easy to use. This tool determines various states of maintenance management and develops control processes and indicators to obtain values to establish various strategies to be adopted. A model that allows unqualified workers, users, and owners to manage the maintenance of heritage buildings simply and effectively by developing the habit and the intention to carry out an optimal maintenance.

\section{AUTONOMOUS MAINTENANCE MANAGEMENT OF A BUILDING}

Maintenance is a building support process considered as a cost. This is the reason why maintenance is minimised, or the maintenance function is outsourced without assessing its impact on the continuous improvement of the building's use and lifespan.

The current market implies to reconsider the current maintenance system in the historic building sector. Maintenance efficiency and competitiveness are achieved by managing building uses appropriately, as well as the maintenance management of the installations, spaces and elements to meet the quality, performance and comfort goals expected [3].

In the industrial sector, pioneer in maintenance management, this development has led to the implementation of the TPM, which emerged in Japan in the core of the Japan Institute of Plant Maintenance [2].

Today, given the importance of continuous improvement management programmes, such as the Lean methodology or the EFQM model that are applied in many companies and entities, it is crucial to consolidate an effective maintenance management of heritage buildings used as assets. This leads to using the TPM as an improvement programme in relation to the maintenance management of any building.

The TPM is the result of the evolution of maintenance management systems: from systems that have been standards for many years to more complex, but highly effective, systems [4]. Traditional maintenance systems have not been removed but included with a new approach.

Based on the philosophy of the TPM applied to buildings, users (workers or others) are the responsible for the rooms, elements, and installations of the building, particularly to detect problems or anomalies before use difficulties are generated. These difficulties could alter the service of the building, as well as its cleaning and appropriate use.

The building sector suggests the application of the TPM as a basis to develop an autonomous maintenance management model of both the various heritage buildings and their assets. An effective and integrated maintenance management is suggested, including the previous types of maintenance, as Fig. 1 shows.

\subsection{Autonomous maintenance of a heritage building}

The importance of the TPM lies on the incorporation of autonomous maintenance by workers themselves. In our adaptation, autonomous building maintenance is carried out by users themselves, playing their respective roles, as far as possible. Thus, all employees are actively 


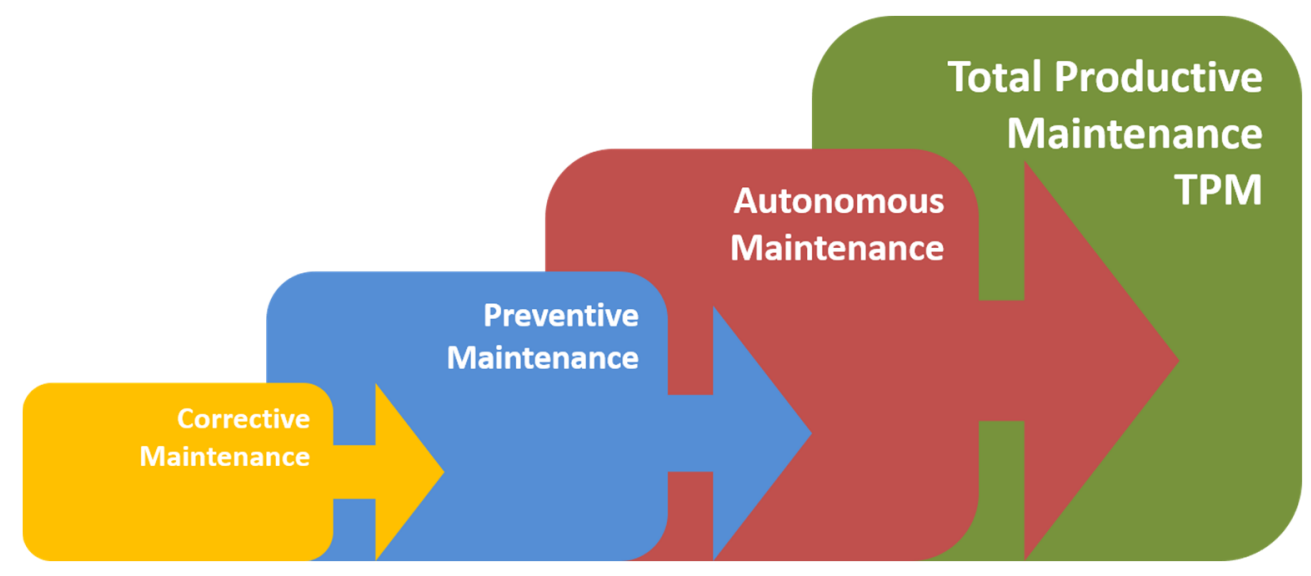

Figure 1: Evolution of maintenance management.

involved, from senior officials to maintenance labourers, going through users. In addition, the goals proposed by the manager of the building are fulfilled, and an own culture that stimulates the teamwork and raises the staff's spirits is developed.

Therefore, the philosophy of the TPM is applied [2]. It adapts the concept of continuous improvement from the maintenance point of view to the total building management, thus leading to the Autonomous Building Maintenance, which will be a new maintenance concept in the building sector. By including the Autonomous Maintenance as an integral and fundamental part of the TPM, the total balance of the maintenance tasks continuously and jointly managed, with the building being used, will be achieved.

Thus, the autonomous maintenance applied to a building is the maintenance in which any worker, even sometimes users, takes on maintenance management tasks based on noticing the need for or the ineffectiveness of maintenance. There is therefore a basic task: noticing the maintenance deviations that could be generated in a building.

For this purpose, the procedures required to contribute to the effectiveness of autonomous management that leads to an autonomous maintenance of heritage buildings are established in each building.

Talking about use in a TPM context is based on finding defects, anomalies, and needs for maintenance that guarantees the use of the building. The sequential description of this philosophy is shown in Fig. 2, which shows that a good use, i.e., a committed work/use, facilitates inspection. Thanks to that inspection, anomalies and precautions that guarantee the use of the area could be found, thus reducing intervention times.

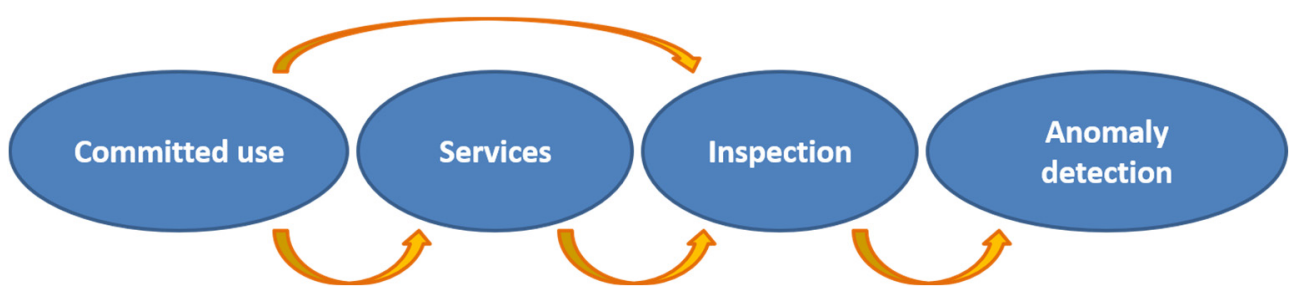

Figure 2: Evolution towards anomaly detection. 
An example of an Autonomous Maintenance action is shown in Table 1, which includes the activities conducted in a possible stage.

Table 1: Example of activities in each stage.

\begin{tabular}{|l|l|}
\hline \multicolumn{1}{|c|}{ Committed use } & \multicolumn{1}{c|}{ Services } \\
\hline Appropriate use & Daily cleaning \\
\hline Immediate notification & Deep cleaning throughout year \\
\hline \multirow{4}{*}{ Inspections } & Cleaning of the inaccessible zones \\
\cline { 2 - 3 } & Cleaning of elements and installations \\
\cline { 2 - 3 } & Generic cleaning due to use \\
\hline Search of visible and invisible defects & Fissures and cracks \\
\hline Checking of installations and elements & Scratches \\
\hline Identification of obstacles hindering cleaning & Hits \\
\hline Checking of measure devices & Broken pieces \\
\hline Checking of tools & Leaks or escapes \\
\hline & Humidities \\
\hline & Weaknesses making tasks difficult \\
\hline & Inaccessibilities \\
\hline
\end{tabular}

2.2 Goals of the TPM in the building sector

The major goals of the TPM applied to a building should be as follows:

- To maximise use effectiveness and guarantee of the building or parts of it and to remove all losses.

- To develop a sense of property in the employees and users of a building though a training and involvement programme.

- To promote a continuous improvement through the activities of small groups, including owners, users, managers, and those responsible for maintenance.

Buildings should have their own definition and view of the TPM, but most should maintain common elements and issues. There are seven key elements in any TPM programme applied to building management (Fig. 3) [5]:

1. Physical resource strategy. The TPM is commonly used to support or to facilitate the principles of quality and Just-in-time (JIT) management. This includes having structures in a cellular configuration and removing redundant steps or tasks. They are also a common part of the plan to include radical improvements in the management methods of a building asset.

2. Responsibility and autonomy. Self-management. The TPM puts the improvement capacity in the hands of employees/users. It guarantees workers' autonomy and responsibility. In addition, the TPM recognises that the employees of an area can teach a lot and learn from others. The whole organisation becomes stronger and receives ideas from small, motivated groups focused on a continuous improvement.

3. Resource planning and programming. The assistance demand for the maintenance department will be significantly increased during the introduction of the TPM, particularly while workers are being trained to increase their awareness and knowledge 
about the building. Afterwards, they will want to quickly correct the causes of any pathology as they discover them.

4. Systems and procedures. A systematic maintenance management should be as effective as possible to reduce the risk of failures. First, the nature of the failure of a specific case should be understood. Then, the solution could be selected based on time, use factors, condition, or any other tactic.

5. Measurements. Measuring the progress of a continuous improvement is also useful for the TPM, including the number of small active groups and their individual and collective progress. From the beginning, disseminating beyond each affected area the good news about the progress will motivate all the members involved in the management of both the maintenance and the building.

6. Continuous improvement teams. An example is RADAR, a concept established by the ISO 9001 standard on Quality Management Systems. RADAR corresponds to the abbreviation that includes five elements: Results, Approach, Deployment, Assessment, and Review.

7. Processes. Processes should be reviewed and rectified in the new climate of responsibility, flexibility, and response capacity. They should be analysed, clearly understood, and redesigned to support the goals of the TPM. Each step should add value and reduce any waste of cost, time, service, quality, or other resources.

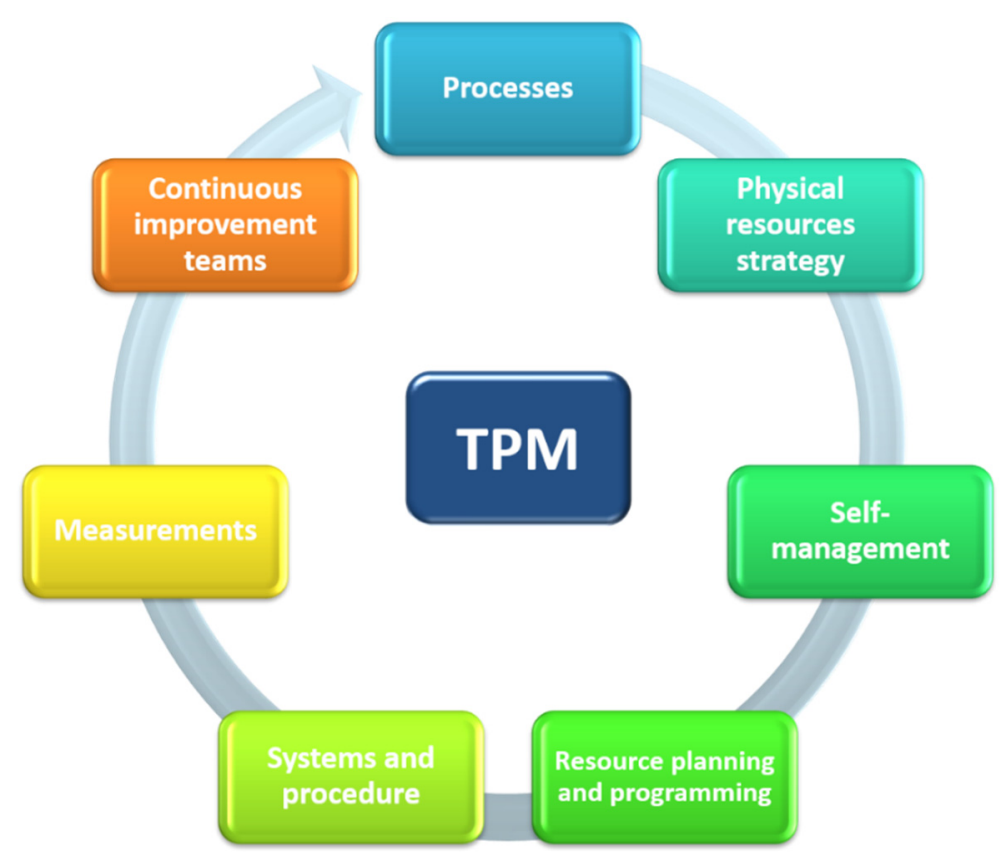

Figure 3: TPM wheel.

\subsection{Implementation of the TPM in a heritage building}

The meaning of the TPM and what can be achieved with it is different in each application. Likewise, the implementation plan should be specific according to each building. 
An implementation plan of the TPM model should consist of four stages that must be carried out by all the people involved in the maintenance management process.

Awareness, education, and training. These are not just essential improvement activities of the TPM but a key pillar that supports the others. Directors, maintenance staff, team leaders, and workers should be involved in the learning process.

Education and training should support the following elements:

- Decentralisation of decisions and authority delegation to employees and users. This will imply to act in an autonomous way, with knowledge and confidence, and as members of a team they know where and when ask for help.

- Maintenance prevention or reduction of the maintenance intervention without sacrificing reliability. This is achieved through both standard operating procedures and systematic analyses of the indicators established.

- Workers' polyvalence (numerous skills) to maximise flexibility, efficiency, and satisfaction in the work of the people involved.

- Result measurements to assess the costs/benefits of the TPM. The successes of the programme are disseminated, and the obstacles are removed to improve the productivity of resources.

Apart from understanding the underlying theory of the TPM, some practical knowledge is required before making changes in the system. Carrying out a pilot maintenance management project will provide ideas and experiences, and confidence will be inspired in the implementation team.

Conducting a previous and posterior study in detail will be very useful for a test. An effective method is to photograph or to film the area to identify defects and damages. The creation of a visual record is part of the process composed of eight steps in a pilot project:

- Education (bases). Internal seminars about the elements and goals of the TPM, and how it is related to both management models and continuous improvement programmes.

- Survey. To determine the more suitable areas for a pilot programme.

- To select the pilot area based on both the successful probability and the potential to improve maintenance management.

- Initial data collection.

- Specific maintenance education. Seminar for the staff responsible for maintenance management.

- Photo tour.

- Training. To establish a training period on maintenance management for the staff.

- Beginning. To select a formal beginning date and to allocate responsibilities.

\section{IMPLEMENTATION OF THE AUTONOMOUS MAINTENANCE MANAGEMENT MODEL IN A HERITAGE BUILDING}

The results are shown in the steps followed to develop the Autonomous Maintenance Management Model in a heritage building. This proposal is the result of the methodology developed. This methodology is based on three pillars:

- Adaptation of the TPM model to the building sector, including autonomous maintenance.

- Exhaustive knowledge of the building, its uses, and possible variables.

- Order of criteria, indicators, measurements, control ways with easy and accessible tools, and result assessment. 
Thus, the autonomous maintenance management model in heritage buildings is obtained. This model aims to be as effective as possible by using the existing resources. The results are presented in the autonomous maintenance management process of a building.

\subsection{Description of the case study}

The autonomous maintenance management model was implemented in the building of the Hernando Colón College (Fig. 4) of the University of Seville due to both the ease to access to maintenance data and the development in process management according to the EFQM excellence model. It is a specific case study, within the heritage buildings of the University of Seville, in operation for more than 70 years.

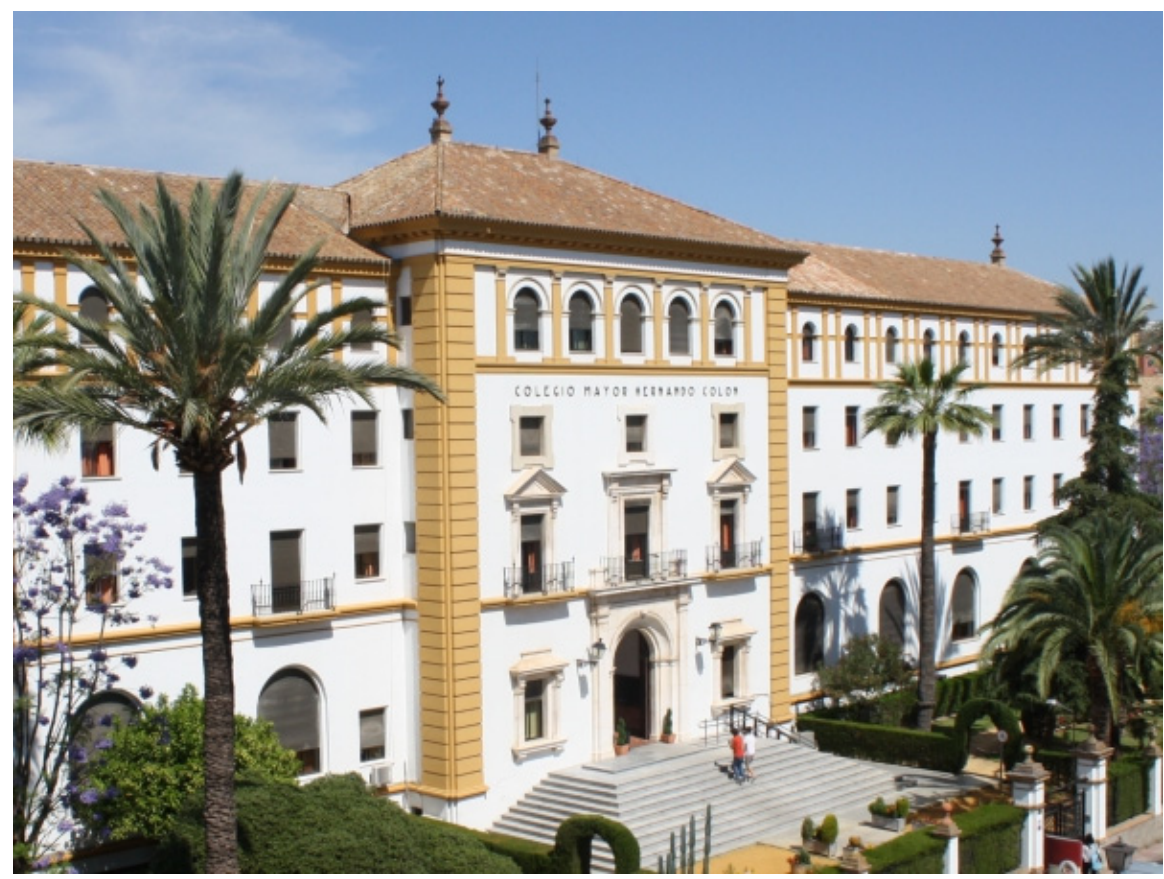

Figure 4: Front view of the Hernando Colón College.

Since the inauguration in 1948, it provides residence to the students and researchers. The building was designed by the architect José Gómez Millán, located in the Reina Mercedes Campus, in a square projected for the Universal Exhibition of 1929, which was called Plaza de los Conquistadores, nearby the Basque Pavilion or the Cordoba Pavilion. This location allowed to provide the Hernando Colón outdoor facilities integrated with the university campus (Fig. 5).

The 3,500 square meters building was designed in a T-shape, with four floors and basement. The last two floors occupy the front part of the building, with a rectangular shape. The ground floor (Fig. 6) and basement are destined to common rooms and services. The first, second (Fig. 7) and third floors allocate 128 rooms, common toilets and showers. The distribution outdoors comprises green areas, swimming pool and sports courts, as well as car parks. 


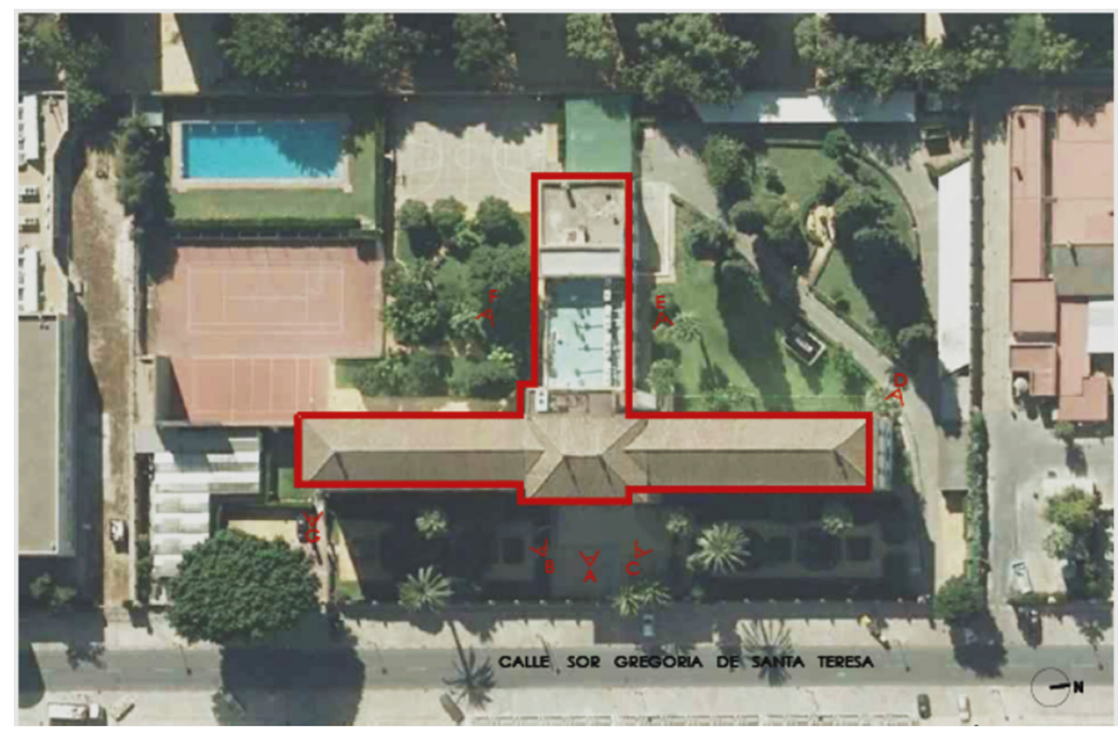

Figure 5: Aerial view of the Hernando Colón College.

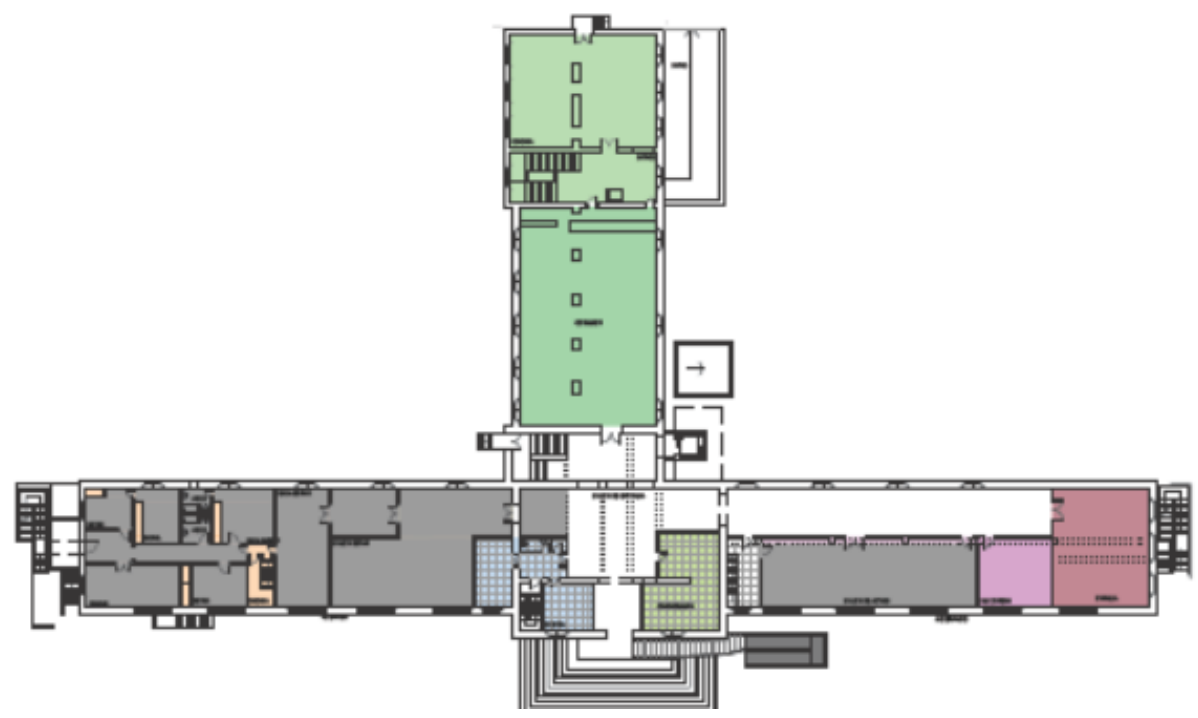

Figure 6: Ground floor plan of the Hernando Colón College.

The structure of the building is made up of load-bearing brick walls and a central reinforced concrete portico on which two-directional slabs rest. The foundation is formed by continuous footings. Two types of roof can be distinguished, a gable roof made of ceramic tiles, which covers the third floor. And a flat roof, which covers the rear area up to the first floor. The building's partitions are mainly made of clad brickwork, with the exception of the third floor, which is made of plasterboard partitions. 


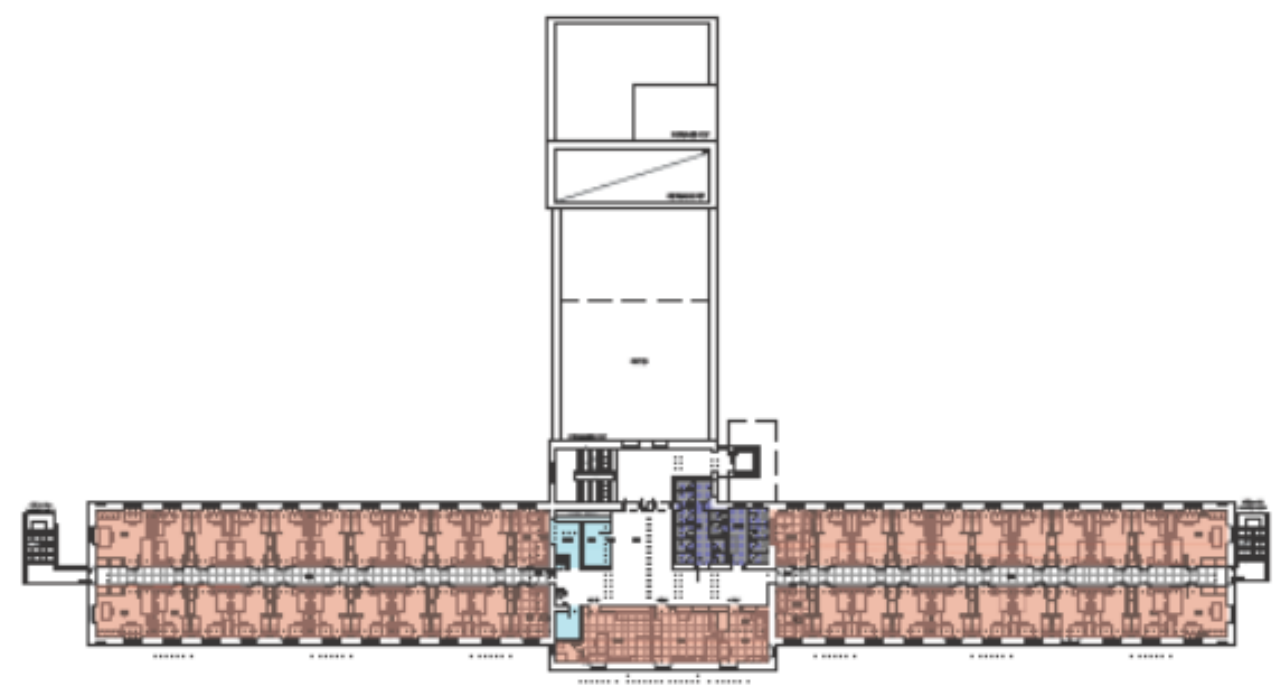

Figure 7: Second floor plan of the Hernando Colón College.

\subsection{Implementation of the process}

The model was implemented as an opportunity to improve the building and was included in the proposals established in the strategic plan in 2015. The starting point was the expertise of the staff, together with the historical data obtained until 2014.

The autonomous maintenance management model defines maintenance criteria, actions, and control indicators, with all of them being both basic to start managing maintenance in a useful way and applicable to the resources available in the centre.

This maintenance management model is susceptible to be modified, thus generating new actions, criteria, and indicators, or modifying those existing. Today the version 02 is applied.

In this version 02, the model is called as Autonomous Maintenance Management Process.

The sequence of the works developed in the experimental stage was based on the sources established by the EFQM Model, perfectly implemented in the centre, and assimilated by all those responsible for its management:

- Performance of the SWOT analysis.

- Performance of the Improvement Opportunity as part of the 2015 strategic plan.

- Writing of the Maintenance Management Model, version 00-2015.

- Implementation of the Maintenance Management Model.

- Analysis of maintenance indicators 2015.

- Review of the Maintenance Management Model, version 00-15.

- Writing of the Maintenance Management Model, version 01-2016.

- Analysis of maintenance indicators 2016.

- Review of the Maintenance Management Model, version 01-16.

- Writing of the Autonomous Maintenance Management Process of the TPM, version 022017. 
Based on the data obtained from the experimental phase (from 2015 to today), in comparison with data from the analytical phase (from 2012 to 2014), maintenance is optimised according to the criteria included in the process that supports the goals of this research work, as Fig. 8 shows. The corrective parts are reduced, and the preventive parts are increased.

Having ended the year 2016, when the experimental phase was finished, the implementation of the model was consolidated, so the model was reviewed by those involved in their implementation.

Like in the previous period based on the analysis of results, there is an improvement (Figs 8 and 9) in comparison with the reference data from the previous years: more information is demanded to establish more references and to achieve more goals.

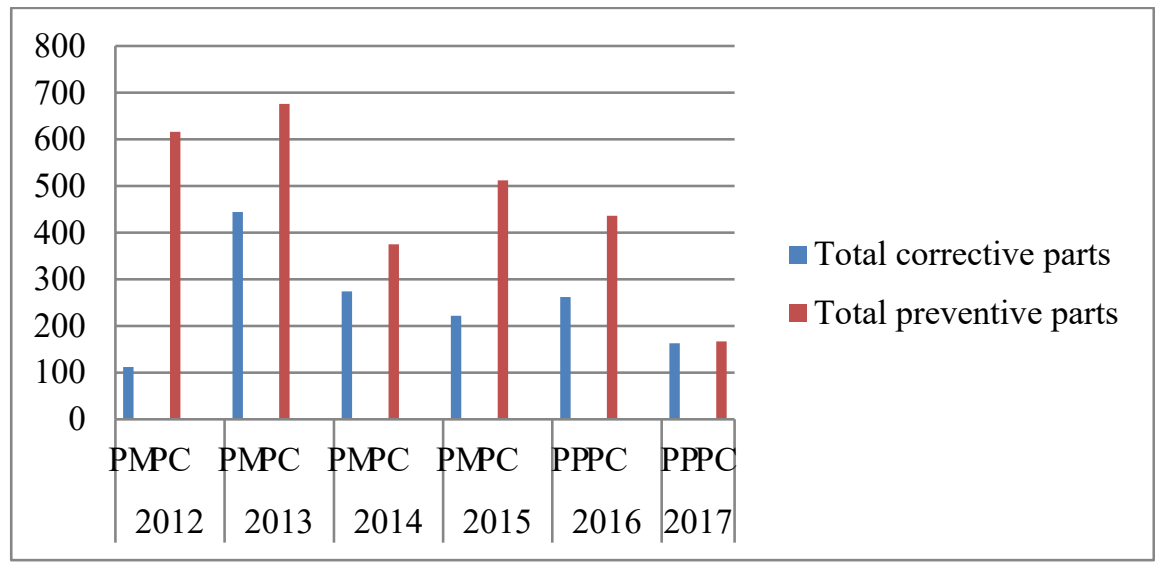

Figure 8: Maintenance tasks carried out in the period 2012-2017 (CMHC).

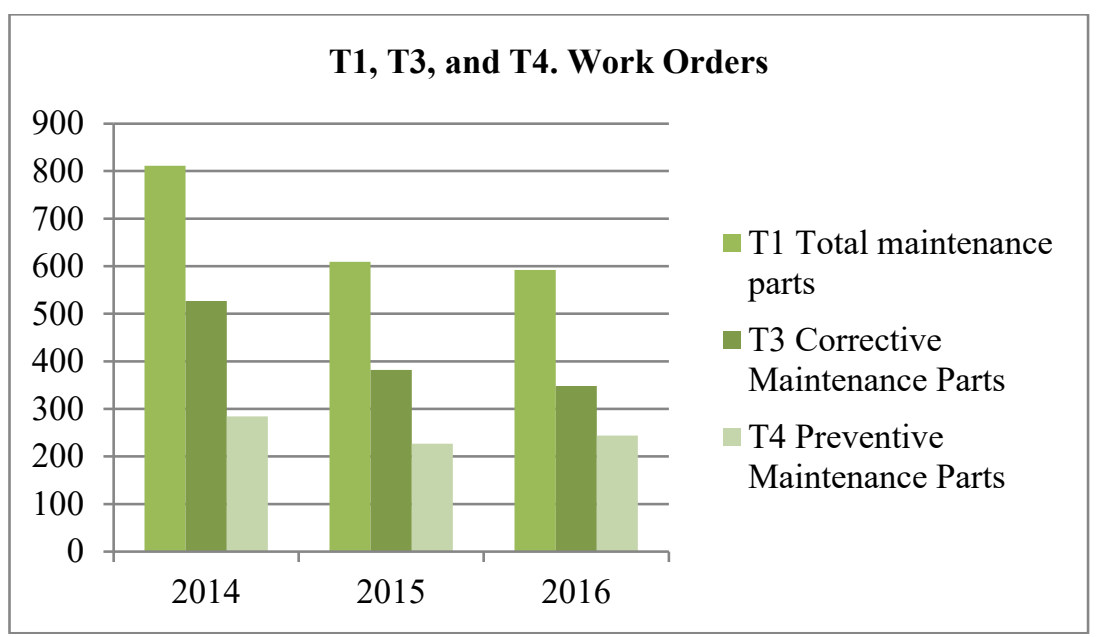

Figure 9: Example of the data obtained in the experimental stage 2 (CMHC). 


\subsection{Model assessment}

The reviews carried out in the implementation of the model and in its maintenance as operating process determined the following aspects to be progressively implemented:

a) Consolidation of the design of the structure and classification of areas, assets that should be maintained, and uses of each area.

b) Programming of the hours of human resource available according to the working day.

c) Implementation of maintenance criteria according to the structure of the model:

- Strategy of the building. Structure of the building.

- Application of self-management.

- Training.

- Planning. Legal preventive maintenance according to frequencies and schedules allocated to the human resource. Gantt diagram.

- Optimal measurements.

- Review at the end of the period established.

d) Increase of the selection of key maintenance management indicators.

e) Use and control of the Excel application to develop a maintenance management database.

f) Control of the annual maintenance. Adding programmed preventive maintenance actions to legal preventive maintenance actions.

g) Control of non-programmed maintenance according to the classification established in the study of the model.

With all this and after the review conducted by the agents involved, the improvement group from the Hernando Colón College assessed the implementation of the model, determining the autonomous maintenance management model implemented in the centre after the experience in the two experimental stages. Moreover, an experimented technical document was developed, which fulfilled all the aspects established in the goals of this work.

The autonomous maintenance management process in a heritage building as a possible, realistic tool directly used in built and in-use buildings, using the human resources available.

By way of summary, the autonomous maintenance management process of the Hernando Colón College is today part of the management operating processes. This process is based on the strategies of the centre and is susceptible of the implementations demanded because of the continuous search of excellence in management.

\section{CONCLUSIONS}

The need for building maintenance management is supported by many research works.

Current concern on sustainability in architectural constructions, apart from the attention paid to energy efficiency, should be included in a minimum maintenance management framework that provides the building with an appropriate life cycle durability, thus reducing the consumption of resources from an ineffective management and increasing at the same time users' satisfaction.

According to our goals, the proposals of this research work are reasonable and in favour of an effective and autonomous maintenance management, thus contributing to the continuous improvement of the management processes implemented.

These results give response to the generation of an autonomous maintenance management model in heritage buildings that is based on use, the human resources available, and building constructive characteristics. A model mainly based on the human factor, assimilating the 
criteria established in the Total Productive Management (TPM) and establishing a continuous improvement process as a global part of the building management.

The model is completed by applying directly the methodology developed, thus leading to the Autonomous Maintenance Management Process of the Hernando Colón College. The goal is to test its implementation in a building in use by both assessing its global effectiveness and proving a possible methodology that can be directly used in heritage and in-use buildings. Furthermore, the human resources available are used, and indicators to establish strategies for an optimal maintenance management are considered, thus impacting the use of the various buildings as less as possible.

\section{REFERENCES}

[1] Ley 38/1999, de 5 de noviembre, de Ordenación de la Edificación, 1999.

[2] Dixon Campbell, J., Orgenización y Liderazgo del Mantenimiento, Edición en., Toronto, 2001.

[3] Martin Ezama, L., Gestión del Mantenimiento en Edificación, COAATIE AL.: Albacete, 2015.

[4] Cuatrecasas, L. \& Torrel, F., TPM en un entorno Lean Management, 2010.

[5] Gonzáléz Fernández, F.J., Teoría y Práctica del Mantenimiento Industrial Avanzado, $4^{\mathrm{a}}$ Edición, Madrid, 2011. 